\title{
OVARIAN MALIGNANCY;
}

IN WOMEN OF REPRODUCTIVE AGE PRESENTING WITH OVARIAN MASS AND FREQUENCY OF FACTORS LEADING TO OVARIAN MALIGNANCY.

1. MBBS, FCPS

Senior Registrar

Lady Wallington Hospital, Lahore.

2. MBBS, FCPS

Assistant Professor

Khyber Medical University

Institute of Medical Science Kohat.

3. MBBS, FCPS

Consultant Gynecologist

THQ Hospital, Shakargarh,

District Narowal.

Correspondence Address:

Dr. Shabana Rafiq

Senior Registrar

Lady Wallington Hospital, Lahore.

Article received on:

17/08/2017

Accepted for publication:

15/11/2017

Received after proof reading:

$31 / 01 / 2018$

\section{Shabana Rafiq ${ }^{1}$, Razia Bibi², Samina Ashraf $^{3}$}

ABSTRACT... Objectives: To determine the frequency of ovarian malignancy in women of reproductive age presenting with ovarian mass and to determine frequency of factors leading to ovarian malignancy. Study Design: Cross sectional study. Setting: Department of Obstetrics \& Gynaecology, Lady Wallington Hospital, Lahore. Period with Dates: From 05.11.11 to 26.06.12. Results: The result of our study reveals majority of the patients between 21-30 years i.e. $45.88 \%(n=39)$, common age was $24.21+3.76$ years, $43.53 \%(n=37)$ were nulliparous (in majority), while frequency of ovarian malignancy in women of reproductive age presenting with ovarian mass was recorded in $14.11 \%(n=12)$ while frequency of factors leading to ovarian malignancy was $91.67 \%(n=11)$ patients were nulliparous while family history of ovarian malignancy was in $8.33 \%(n=1)$ patients. Conclusions: The frequency of ovarian malignancy is higher among reproductive age females with increased risk of nulliparity.

Key words: $\quad$ Ovarian Malignancy, Frequency, Nulliparity, Family History.

Article Citation: Rafiq S, Bibi R, Ashraf S. Ovarian malignancy; In women of reproductive age presenting with ovarian mass and frequency of factors leading to ovarian malignancy. Professional Med J 2018; 25(2):237-241.

DOI:10.29309/TPMJ/18.4254

\section{INTRODUCTION}

Among the gynaecological malignancies, ovarian malignancy is the most lethal and has the highest mortality rates. ${ }^{1}$ Ovarian malignancy has generally has been considered to be the disease of elderly postmenopausal women but literature shows an alarming fact that up to $20 \%$ of ovarian malignancy is found in women below 40 years of age. ${ }^{2}$ Young age of the women, future fertility concerns and inherent mortality related to a malignant disease triggered us to undertake this study.

Majority of the malignant ovarian tumors in young girls between 15-21 years of age are of germ cell origin and between 21-40 years of age is epithelial in origin. It is tragic to note that most cases of epithelial ovarian cancer are already advanced at first presentation. ${ }^{3}$ The reasons for late diagnosis are twofold. First and foremost is the non availability of a reliable screening program and second reason is the late development of symptoms like abdominal mass, pain abdomen and menstrual irregularity. By the time symptoms appear, the tumor has already advanced with a possible intra peritoneal spread. This is the reason why ovarian malignancy has historically been called a silent killer. ${ }^{4}$

By early diagnosis of ovarian cancers, life expectancy can be improved but at present, no reliable method of identifying the ovarian cancer at early stage is available. However, early identification may enable clinicians to improve the prognosis. ${ }^{5}$ So there is a need to identify women at risk of ovarian cancer and to develop a reliable screening program so that young patient with ovarian cancer may be early. In gynaecological history, nulliparity is a leading factor for epithelial ovarian cancers, meaning thereby that the risk decreases as the parity increases. Typically having had one or two children is associated with a decrease in risk of approximately $30 \%$ and having had 3 or more children is associated with a decrease in risk of approximately $60 \% .{ }^{6}$ It is well known clinically observation that ovarian cancer tends to aggregate in families. At least 1 of 10 patients with ovarian cancer is estimated to develop their tumor because of heredity with 
breast and ovarian cancer and hereditary non polyposis colorectal cancer. Cancer at young age is hallmark of heredity. Musinous and endometrioid cancer diagnosed in $27 \%$ and $16 \%$ of tumor before 40 years. $^{2}$

Current screening \& early detection of ovarian cancer includes a combination of ovarian cancer symptoms complex with periodic serum CA125 levels \& transvaginal ultrasound scan in women with a family history of ovarian cancer. Universal screening in the general population however is not cost effective and is not recommended.

Symptom complex includes:

1. Abdominal or pelvic pain,

2. Bloating,

3. Difficulty during eating the food or feeling of being full quickly

4. Urinary symptoms including frequency or urgency

The above symptoms are known as Ovarian Cancer Symptoms Index (OCSI). Specificity of OCSI index alone was recorded $90 \%$ in women presenting after 50 year of age while $86.7 \%$ in less than 50 years aged females. However, OCSI score in combination with CA125 may improve the sensitivity of identifying ovarian cancer in females enrolled in high-risk screening programmes. ${ }^{7,8,9}$

Ovarian malignancy is common in postmenopausal patients as shown in previous literature but in our clinical practice, diagnosed patients with ovarian malignancy at reproductive age are being common and purpose of this studies is to calculate the percentage in out population.

We have yet to get the results of our study; however we are anticipating that the results will help us in identifying the risk factors predisposing to ovarian malignancy in these young women. Knowledge of these factors coupled with standard ovarian cancer screening protocols may lead to early detection of patient with ovarian cancer which are definitely improved the prognosis. Experience and the knowledge thus gained will also help us in set up an ongoing screening program for ovarian cancer in out population.

METHODOLOGY

Study Design

Cross sectional study

Setting

Lady Willington Hospital, Lahore.

Duration with Dates

From 05.11.11 to 26.06.12

\section{Sample Size}

Sample size of 85 cases was calculated with $95 \%$ confidence level, $6.5 \%$ margin of error and taking expected percentage of family history i.e. is $10 \%$ in women of reproductive age presenting with ovarian mass.

All patients presenting to our hospital were between 15-45 years of age with a clinical and ultrasound diagnosis of non inflammatory ovarian mass were included in the study. We excluded those patients who did not give consent to be part of the study and those with uncertain diagnosis were excluded. After taking Demographic history (name, age, marital status, parity, address) and an informed consent was taken from all the patients that their clinical data was used in a research study. A proforma was devised to collect clinical data and results of investigation reports. Histopathology reports of all the patients were collected from pathology department to measure frequency of malignancy. Then various factors like reproductive history and family history was recorded.

\section{RESULTS}

A total of 85 cases fulfilling the inclusion/exclusion criteria were included in the study to determine the frequency of ovarian malignancy in women of reproductive age presenting with ovarian mass and to determine frequency of factors leading to ovarian malignancy.

\section{Age Distribution of the Patients}

Age distribution of the patients was done, where majority of the patients were recorded between $21-30$ years i.e. $45.88 \%(n=39), 27.06 \%(n=23)$ 
were between $31-40$ years, $21.18 \%(n=18)$ were between $15-20$ years and only $5.88 \%(n=5)$ were between 41-45 years, mean and sd was calculated as $24.21+3.76$ years. (Table-I)

\begin{tabular}{|l|c|c|}
\hline \multicolumn{1}{|c|}{ Age (in years) } & No. of patients & \%age \\
\hline $15-20$ & 18 & 21.18 \\
\hline $21-30$ & 39 & 45.88 \\
\hline $31-40$ & 23 & 27.06 \\
\hline $41-45$ & 05 & 5.88 \\
\hline Total & 85 & 100 \\
\hline Mean \& sd & \multicolumn{2}{|c|}{$24.21+3.76$} \\
\hline \multicolumn{2}{|r|}{ Table-I. Age distribution $(n=85)$} \\
\hline
\end{tabular}

\section{Distribution of Patients According to Parity}

Distribution of patients according to parity reveals $43.53 \%(n=37)$ nulliparous (in majority), $40 \%(n=34)$ were between para $1-2,9.41 \%(n=8)$ between para $3-4$ and $7.06 \%(n=6)$ with para $>5$. (Table-II)

\begin{tabular}{|l|c|c|}
\hline \multicolumn{1}{|c|}{ Parity } & No. of patients & \%age \\
\hline Nulliparity & 37 & 43.53 \\
\hline Para 1-2 & 34 & 40 \\
\hline Para 3-4 & 08 & 9.41 \\
\hline Para $>5$ & 06 & 7.06 \\
\hline Total & 85 & 100 \\
\hline Table-II. Distribution of patients according to parity \\
$(\mathbf{n}=85)$
\end{tabular}

\section{Frequency of Ovarian Malignancy}

Frequency of ovarian malignancy in women of reproductive age presenting with ovarian mass was the variable of interest of the study which was recorded in $14.11 \%(n=12)$ while $85.89 \%(n=73)$ had no ovarian malignancy. (Table-III)

\begin{tabular}{|c|c|c|}
\hline Ovarian malignancy & No. of patients & \%age \\
\hline Yes & 12 & 14.11 \\
\hline No & 73 & 85.89 \\
\hline Total & 85 & 100 \\
\hline
\end{tabular}

Table-III. Frequency of ovarian malignancy in women of reproductive age presenting with ovarian mass $(n=85)$

\section{Frequency of Factors Leading to Ovarian Malignancy}

Frequency offactorsleading to ovarian malignancy was also recorded which shows $91.67 \%(n=11)$ patients were nulliparous while family history of ovarian malignancy was in $8.33 \%(n=1)$ patient. (Table-IV)

\begin{tabular}{|l|c|c|}
\hline \multicolumn{1}{|c|}{ Factors } & No. of patients & \%age \\
\hline Nulliparity & 11 & 91.67 \\
\hline Family history & 01 & 8.33 \\
\hline Total & 12 & 100 \\
\hline \multicolumn{2}{|c|}{ Table-IV. Frequency of factors leading to ovarian } \\
malignancy $(\mathrm{n}=85)$
\end{tabular}

\section{DISCUSSION}

Ovarian malignancy is found as a common problem in postmenopausal women, but in our clinical practice, diagnosed patients with ovarian malignancy at reproductive age are being common, so it was the need to calculate the magnitude of this problem in our population.

In our study, frequency of ovarian malignancy in women of reproductive age presenting with ovarian mass was recorded in $14.11 \%(n=12)$ while frequency of factors leading to ovarian malignancy was $91.67 \%(n=11)$ patients were nulliparous while family history of ovarian malignancy was in $8.33 \%(n=1)$ patients.

Omanska $\mathrm{K}^{10}$ demonstrates that up to $20 \%$ of ovarian malignancy is found in women below 40 years of age, ${ }^{2}$ our results are in agreement with these findings as we recorded $14.11 \%$ of the patients having ovarian cancer with reproductive age group.

Surprisingly, Rashid S and workers ${ }^{10}$ at Lahore recorded $4.8 \%$ ovarian cancer among all females' malignancies, which is in contrast of the results of our study, the reason behind this disagreement may be due to reason that the study was conducted in 1988, at that time the incidence may be lower while another recent study in Pakistan by Irum Sohail and colleagues ${ }^{11}$ at Rawalpindi between 2002-2009 recorded the rate of malignancy in $18 \%$ which is in agreement with the result of the current study.

The risk of ovarian cancer is found to be lower by factors which may interrupt ovulation process like use of oral contraceptives, pregnancy and breastfeeding, while those that prolong 
exposure to ovulation such as nulliparity and infertility increase risk, ${ }^{12-15}$ these findings are in agreement with the result of the current study, as we recorded $91.67 \%$ of the ovarian cancer were among nulliparous.

A lower risk of ovarian cancer is recorded in females given birth when compared to those who have not. ${ }^{16} \mathrm{~A}$ dose response correlation is found between higher risk and lower number of children. Authors reveal a reduced risk for those with incomplete pregnancies. ${ }^{17-18}$

The females who have a first-degree relative diagnosed with ovarian cancer have a three to four-fold increased risk of developing the disease compared with women with no family history, although only about $10 \%$ of ovarian cancer cases occur in women with a family history. ${ }^{19-20}$ The known susceptibility genes (e.g. BRCA1 and BRCA2) explain less than $40 \%$ of the excess risk of familial ovarian cancer. These estimates suggest that more research is needed, however or results regarding family history are comparable as we recorded $8.33 \%$ of the patients who had family history of ovarian cancer.

Our anticipation that the results may help us in identifying the risk factors predisposing to ovarian malignancy in reproductive age women and knowledge of these factors coupled with standard ovarian cancer screening protocols would lead to early detection of patient with ovarian cancer which will definitely improve the prognosis is justified. Experience and the knowledge thus gained on the basis of the results of the will also help in our set up an ongoing screening program for ovarian cancer in out population.

\section{CONCLUSION}

The frequency of ovarian malignancy is higher among reproductive age females with increased risk of nulliparity. So, it is recommended that every reproductive age female who present with ovarian mass must be screened for ovarian malignancy. However, it is also required that every setup should have their surveillance in order to know the frequency of the problem.

Copyright@ 15 Nov, 2017.
REFERENCES

1. Chan J K, Urban R, Cheung M K, Osann K, Husain A. Ovarian cancer in younger vs older women: a population-based analysis. $\mathrm{Br} J$ Cancer 2006; 95(10):1314-20.

2. Omanska K, Malander S, Masback A, Nilbert M. Ovarian cancer at Younger Age: The contribution of mismass- repaired defects in a population-based series of epithelial of ovarian cancer before age 40 . Int J of Gynae cancer 2007; 17:789-93.

3. Shah S, Hishikar VA. Incidence and management of ovarian tumors. Bombay Hospital J 2008; 50:1-4.

4. Jasen P. From the "Silent Killer" to the "Whispering Disease": Ovarian cancer and the uses of metaphor. Med Hist 2009; 53(4):489-512.

5. Goff BA, Mandel LS, Drescher CW, Urban N, Gough S, Schurrman KM. Development of an ovarian cancer symptoms index: possibilities for earlier detection. Cancer 2007; 109(2):221-7.

6. Shaw WR, Luesley D, Monga A. Ovarian Cancer. In: Shaw WR, Luesley D, Monga A. Editors. Gynaecology- 4th ed. China: Churchill living stone Elsevier; 2011:P.516-7.

7. Basu P, De P, Mandal S, Ray K, Biswas J. Study of 'patterns of care' of ovarian cancer patients in a specialized cancer institute in Kolkata, eastern India. Indian J cancer 2009; 46(1):28-33.

8. Granstrom C, Sundquist J, Hemminki K. Population attributable fractions for ovarian cancer in Swedish women by morphological type. $\mathrm{Br} \mathrm{J}$ Cancer 2008; 15; 98(1):199-205.

9. Monica R. McLemore RN, Christine Miaskowski RN, Bradley E, Aouizerat, Lee-may Chen. Epidemiologic and genetic factors associated with ovarian cancer. Cancer Nurs 2009; 32(4):281-90.

10. Rashid S, Sarwar G, Ali A. A Clinico-Pathological study of ovarian cancer mother \& child Dec 1998; 13(4):117-25.

11. Sohail I, Hayat Z, Saeed S. A comparative analysis of frequency and patterns of ovarian tumours at a tertiary care hospital between two different study periods (2002-2009). JPMI 2012; 96:196-200.

12. Salehi F, Dunfield L, Phillips KP, Krewski D, Vanderhyden BC Risk factors for ovarian cancer: an overview with emphasis on hormonal factors. Toxicol Environ Health B Crit Rev 2008; 11(3-4):301-21.

13. Fathalla MF. Incessant ovulation-a factor in ovarian neoplasia? Lancet 1971; 2(7716):163. 
14. Hennessy BT, Coleman RL, Markman M. Ovarian cancer. Lancet 2009; 374(9698):1371-82.

15. Sueblinvong T, Carney ME. Current understanding of risk factors for ovarian cancer. Curr Treat Options Oncol, 2009;10(1-2):67-81.

16. Kurian AW, Balise RR, McGuire V, Whittemore AS. Histologic types of epithelial ovarian cancer: have they different risk factors? Gynecol Oncol, 2005; 96(2):520-30.

17. Riman T, Dickman PW, Nilsson S, Correia N, Nordlinder $\mathrm{H}$, Magnusson CM, Persson IR. Risk factors for invasive epithelial ovarian cancer: results from a Swedish case- control study. Am J Epidemiol, 2002; 156(4):363-73.
18. Whittemore A, Harris R, Itnyre J, Collaborative ovarian cancer group. Characteristics relating to ovarian cancer risk: Collaborative analysis of 12 US casecontrol studies. Am J Epidemiol, 1992; 136(4):1184203.

19. Gayther SA, Pharoah PD. The inherited genetics of ovarian and endometrial cancer. Curr Opin Genet Dev, 2010;20(3):231-8.

20. Granstrom C, Sundquist J, Hemminki K. Population attributable fractions for ovarian cancer in Swedish women by morphological type. $\mathrm{Br} \mathrm{J}$ Cancer, 2008; 98(1):199-205.

\title{
Wise men learn by other men's mistakes, fools by their own.
}

\author{
- Italian Proverb -
}

\begin{tabular}{|c|l|l|l|}
\hline \multicolumn{3}{|c}{ AUTHORSHIP AND CONTRIBUTION DECLARATION } \\
\hline Sr. \# & \multicolumn{1}{|c|}{ Author-s Full Name } & Contribution to the paper & Author=s Signature \\
\hline 1 & Dr. Shabana Rafiq & Data collection & \\
\hline 2 & Dr. Razia Bibi & Data collection & Sanins \\
\hline 3 & Dr. Samina Ashraf & Data collection & Saris. \\
\hline
\end{tabular}

